\title{
Caregiving Involvement, Job Condition, and Job Satisfaction of Infant-Toddler Child-Care Teachers in the United States
}

\author{
Ziarat Hossain, ${ }^{1}$ Elizabeth Noll, ${ }^{2}$ and Maribel Barboza ${ }^{1}$ \\ ${ }^{1}$ Department of Individual, Family and Community Education, University of New Mexico, Simpson Hall, MSC05 3040, Albuquerque, \\ NM 87131, USA \\ ${ }^{2}$ Department of Language, Literacy and Sociocultural Studies, University of New Mexico, Albuquerque, NM 87131, USA
}

Correspondence should be addressed to Ziarat Hossain, zhossain@unm.edu

Received 9 March 2012; Accepted 16 May 2012

Academic Editor: Alex W. H. Chan

Copyright () 2012 Ziarat Hossain et al. This is an open access article distributed under the Creative Commons Attribution License, which permits unrestricted use, distribution, and reproduction in any medium, provided the original work is properly cited.

This study explored the degree to which infant-toddler child-care teachers were involved in their caregiving tasks, the nature of their job condition, and the relationships among caregiving involvement, SES variables (e.g., age, income, education, and work hours), and job condition including job satisfaction, burnout, and quitting behavior. Forty-one teachers from 10 daycare centers in small towns of the Southwest participated in the study. Results indicate that there was a high level of caregiving involvement and job satisfaction among the teachers. However, most teachers were dissatisfied with their current income levels, showed a moderate level of burnout, and yet did not express their intention to quit their present job. Correlation analyses reveal that teachers' job satisfaction was positively related to their interaction with children and colleagues, resources, and training but negatively correlated to burnout and quitting behavior. Teachers' burnout and quitting behavior were negatively correlated to their interaction with children and colleagues, resources, training, and income. While the desire to work with children had a significant impact on teachers' job satisfaction and burnout, income and level of collegiality significantly predicted their quitting behavior.

\section{Introduction}

Although research reports on the impact of daycare programs on children's early development and education are available, little research has been done on the experiences and characteristics of infant-toddler child-care teachers, particularly those residing in small urban communities in developed societies. The present study is designed to explore daycare teachers' work environment in rural towns of the United States. Modern economic and social conditions have made center-based daycare services essential in the lives of many Americans [1-3]. The commercial daycare sector has evolved to provide care for children whose mothers work outside the home and to create jobs for a number of people, mainly, women who work as child-care teachers and/or caregivers. In 1863, the first commercial daycare center in the United States was opened for the children of mothers who were employed by hospitals and for the children whose mothers made clothing for Civil War soldiers $[4,5]$. Although the Lanham Act of 1941 considerably involved the federal government in financially supporting daycare programs in the country, government funding was reduced substantially in the 1960s, especially when compared to private sector funding. This trend has continued and has negatively affected the quality of daycare services, as well as the productivity of more than $57 \%$ of mothers with children under 2 years of age who are currently engaged in the paid labor force [6-9].

The realities of today's economic development and women's schooling have changed the traditional gender roles in society where mothers often need and/or desire to be economically independent. Also, increasing economic hardships and the growing divorce rate compel parents, especially single parents, to take on employment. Under these circumstances, daycare has become an aggregate effort and function of families, daycare workers, and institutions [10-12]. Under such a tridimensional system (i.e., family, teacher, and the government) of involvement, daycare has become an integral component of our social infrastructure. Realizing the necessity of center-based daycare services, child and family scholars argue that efforts should be focused 
on developing an effective daycare system that serves the custodial and developmental needs of children. Such an approach to daycare can dispel the view that child-care teachers are mere "baby-sitters" by recognizing their vital contributions toward the social, personal, and intellectual development of children $[13,14]$.

\section{Literature Review}

Child-care teachers serve as a temporary replacement for a child's parents, especially the mother, who is the principal source of nourishment, comfort, security, attachment, and love for that baby [11]. A teacher assumes the obligation to fulfill children's basic needs and help facilitate their physical, emotional, intellectual, and social development [1$3,15]$. In other words, a teacher takes on a large share of the work involved in the upbringing of a child attending daycare. Teachers' qualifications are very much related to the quality of a childcare service and, by extension, the quality of a child's upbringing [16-18]. Typically, an involved daycare teacher provides care to young children, maintains contact with their parents or guardians to discuss the children's progress, and communicates children's needs with the parents through parent-teacher conferences or informal meetings [1-3].

The level of education and quality in training of daycare teachers are highly significant as these individuals are responsible for providing care to a new generation. However, training and qualification requirements vary among states. Some states may require just a high school diploma, while other may require community college courses, or a college degree in child development or early childhood development [1-3]. It is important that young children receive proper care to acquire social, cognitive and intellectual skills needed to understand and interact with their environment. Although children may learn without direct instruction, they develop more fully with educated guidance [19]. Piaget [20] believed that early childhood teachers should be highly intellectual with knowledge in philosophy and psychology. This view was strongly reinforced by the National Child Care Staffing Study and the subsequent research that it inspired. Findings from prior research have consistently demonstrated that skilled and educated childcare staff produce higher quality programs for children [21-24]. Besides academic knowledge, teachers should possess such human qualities as motivation, truthfulness, sensitivity, understanding, and lovingness as these human qualities are critical when children need care and attention [25]. The importance of a teacher's nurturing behavior in childcare and development cannot be overemphasized, and effective teachers must be responsive to the needs of the children.

Quality of care is the combined function of several factors like teacher-infant ratio, staff turnover, and child development training for teachers [18, 25, 26]. Honig [25] emphasized that the staff's creativity and stability are necessary to comfort a baby separated from employed parents. However, current resources in the childcare field are so inadequate that funding quality programs and keeping care affordable while adequately compensating staff has become difficult in the extreme [27]. Chronic underfunding of daycare services cannot be overcome by mere creativity, and decreases in program quality and staff turnover situations are more likely to take place where programs are underfunded and teachers remain underpaid.

About 1.4 million and 1.3 million jobs were held by preschool teachers and child-care teachers in the United States in 2006 and 2008, respectively. Employment of childcare teachers continued to grow over the years and it is projected to increase by $11 \%$ between 2008 and 2018 [1-3]. Currently, about $19 \%$ of all child-care teachers are employed in child daycare services and many of them are dissatisfied with their jobs and suffer burnout mainly due to low pay and stressful job conditions [1-3]. Scholars argue that the feelings of dissatisfaction and burnout may lead to actual quitting, and an increasing quitting syndrome is detrimental to the philosophy of quality and consistent daycare. The annual rate of turnover in daycare is very high — at least $40 \%$ - primarily due to low wages $[23,28]$. Daycare is one of the lowest of the low paid occupations in the country. Currently, wage differences within the child-care field reflect the educational attainment of the teacher and the type of daycare center involved. Some economists and policy makers argue that most of the teachers are women with little to no education and training, and, therefore, low wages are reasonable for them [29].

Child and family experts, however, suggest that the wages of early daycare and education staff should be linked to similarly educated elementary school teachers [27]. In fact, child-care teachers' wages have historically been about half that of local public school teachers' wages [30]. The overall median annual earnings of child daycare teachers were just $\$ 19,300$ in 2010 . The middle $50 \%$ earned between $\$ 17,210$ and $\$ 23,830$ while the lowest $10 \%$ earned less than poverty wages at $\$ 15,900$ for a family of three. Only the highest $10 \%$ earned more than $\$ 29,280$ [1-3]. While the entry-level educational requirements for elementary school teachers is generally higher than that of most daycare teachers, the income difference is nonetheless startling when one compares the above reported numbers with the estimated average salary of public elementary and secondary school teachers in the 2008-2009 school year-\$56,050 [1-3]. The low income potential for daycare teachers produces an all too common scenario in which many "burnt out" teachers quit to look for better paying jobs, thus leaving the quality and stability of daycare services in jeopardy.

In fact, "burnout" has received considerable attention in the socio-psychological and socio-organizational literature since the early 1970s [31, 32]. Most of the research on burnout has been directed toward two areas: helping professionals (e.g., counselors, teachers, social workers, school administrators, psychologists) and public employees (e.g., police officers, air traffic controllers, appointed officials, public health workers) $[33,34]$. Yet, extant research suggests that daycare teachers are more likely to experience burnout than any other professional $[35,36]$. Job burnout is related primarily to sustained stress, which causes both physical and emotional exhaustion, depersonalization, and low levels of a sense of personal accomplishments [12, 37]. African 
American caregivers experience higher levels of depersonalization and emotional exhaustion than Caucasian American teachers, and about $80 \%$ of child-care professionals had low levels of a sense of personal accomplishment [38].

In the case of daycare services, inadequate work environment, low wages, constant work pressure, and a steady flow of administrative issues promote dissatisfaction and turnover among child-care teachers [36, 39]. Scholars emphasize that burnout is an inherent and stress-producing conflict between the professionals' requirement to offer their services and the reality that they can never give enough $[12,40]$. Dworkin [31] indicated a similar notion when defining teachers' burnout in terms of powerlessness and meaninglessness that are indeed indicative of job turnover. Also, interactions with superiors, colleagues, and children at the same time may cause child-care teachers to develop role conflicts and stress when issues of control and organizational conditions do not meet their expectations [41]. These types of challenging job conditions may cause high turnover rates among child-care teachers since highly trained teachers would decide to leave the profession if they were making low wages [42]. Others observe that sociodemographic factors such as company tenure, age, gender, marital status, and education are not related to the level of job satisfaction of a child-care teacher [43].

\section{The Present Study}

As we have indicated earlier, systematic investigations of the nature of daycare work environments especially in small cities in the United States are very limited. In recent years, because of the rapid growth of these small communities, mainly due to in-migration of families from other cities in the country, the need for daycare centers has been increasing. This exploratory study assesses infant-toddler child-care teachers' reports of their work environment in small urban communities located in the southwest region of the United States.

\section{Research Objectives}

The present study was designed to explore the following research objectives.

(1) The degree to which infant-toddler child-care teachers are involved in their caregiving tasks.

(2) The nature of their current job condition, including job satisfaction, burnout, and quitting behavior.

(3) The relationship among caregiving involvement, job condition, and SES variables (e.g., age, income, education, work hours).

For the first research objective, descriptive analyses (e.g., means, SDs) have been used to report the extent to which research participants described their involvement in caregiving tasks, job conditions, and salary satisfaction. For the second objective, Pearson correlation coefficients have been calculated at the 0.05 level of significance to explore the associations among caregiving involvement, job conditions, and SES variables. For the third objective, three multiple regressions at the 0.05 level of significance have been conducted to find out the influence of selected SES and job conditions on participants' perceptions of job satisfaction, job burnout, and job quitting measures.

\section{Methods}

5.1. Participants. Forty-one infant-toddler child-care teachers from 10 daycare centers in three rural towns of the Southwest participated in this study. From each participating center, all the full-time and assistant teachers working in the infants and toddlers' sections were interviewed. There were only three assistant teachers who worked full-time and their education and income were similar to the average of the entire sample. All respondents were female teachers and had worked at least six months in the current daycare centers at the time of the survey. In the current analysis, we excluded data from six participants who did not work exclusively in the infant and toddler section.

Demographic statistics show that teachers vary considerably in age $(M=35.33, \mathrm{SD}=11.37)$ and experience ( $M=7.06$ years, $\mathrm{SD}=8.04$ years $)$. Twenty-six respondents were married, ten were single, and five were divorced. Work schedule data proved more standardized with each teacher working between 4 and 5 days per week $(M=4.83, \mathrm{SD}=$ $.38)$ and 6 to 10 hours per day $(M=8.29, \mathrm{SD}=.87)$. Participants' reports suggest that 29 were Euro-Americans, 10 were Hispanics, one was American Indian, and the ethnicity of one participant was not reported. The individual median income was $\$ 13,500$ per year. Ten respondents had received a bachelor degree, and the mean number of years of schooling completed was 14.21 ( $\mathrm{SD}=2.43$ ). About $88 \%$ of the respondents had taken specialized educational courses such as early childhood development, daycare management, parenting, special education, nutrition, nursing, and social work.

5.2. Procedures. A trained research assistant personally contacted all the participating daycare centers and left the questionnaires with the teachers to be filled out by them. They were instructed to put the completed questionnaires in a supplied envelope that the research assistant would pick up from the center in two weeks. However, this procedure produced very little success in getting responses from the teachers. Therefore, the research assistant personally interviewed each infant-toddler child-care teacher separately. The research assistant was a male college student majoring in early childhood education and was familiar with the daycare program in the region. In view of availability and minimal interference with work responsibility, participants were interviewed during their lunch break at work and it took about 30 minutes to complete one interview. All personally contacted teachers in each center participated in the study.

\section{Measures}

We used two questionnaires, Sociodemographic Questionnaire and Infant-Toddler Caregiving Questionnaire, to collect data from the participants. 


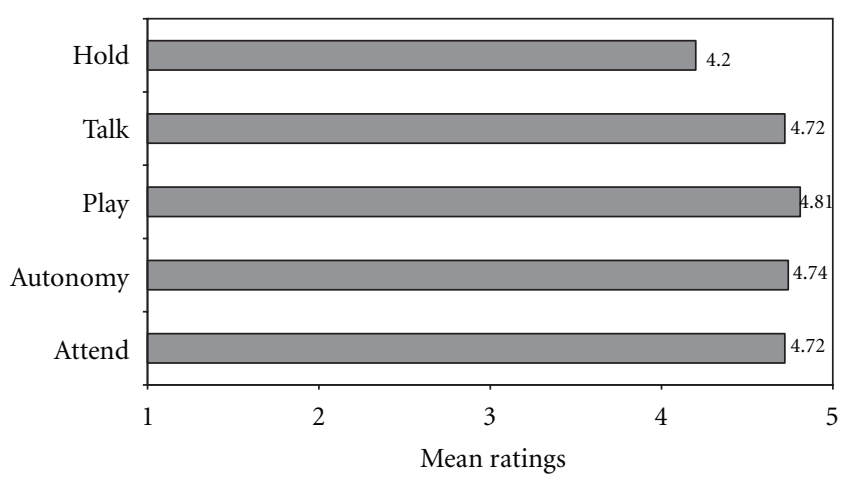

Figure 1: Mean ratings ( $1=$ never to 5 = always $)$ for caregivers' involvement in childcare measures.

6.1. Sociodemographic Questionnaire. The sociodemographic questionnaire contained 10 items concerning age, gender, education, training, special courses, working days and hours, income, marital status, total length of employment, and length of employment at current place.

6.2. Infant-Toddler Caregiving Questionnaire. A significant amount of research has been conducted on the quality of child-care and teachers' work environment in the United States $[16,18,24,44-49]$. Some of these studies have shown relationships between care providers' characteristics (e.g., education, training, caregiving) and the quality of the care [45]. Several projects previously employed measures such as the Caregiver Interaction Scale [44] and the Positive Caregiving Checklist [48] to examine child-care teachers' caregiving behavior and care quality. Unlike the current study, the core purpose of the above mentioned projects and measures was to address quality issues of child care. The assessment of infant-toddler teachers' caregiving behaviors and job conditions was not done consistently across studies.

Therefore, conceptualizing from previous measures on care providers' positive caregiving and interactions with young children $[44,48,50,51]$, the current questionnaire was developed to assess infant-toddler teachers' care behaviors, job conditions, and job satisfaction. This pilot-level questionnaire is primarily a global index of teachers' care involvement with children, and, hence, a pretest of the questionnaire was conducted prior to the administration of it. The first author and a trained research assistant visited a daycare center (which is not included in the sample) for two days, during which two teachers were interviewed with the constructed questionnaire. The pretest provided opportunities to effectively edit the questionnaires, clarify several ambiguous questions, and economize the duration of the interview.

The Infant-Toddler Caregiving Questionnaire consists of three major sections. The first section of the questionnaire comprises five Likert-type items designed to assess the degree to which child-care teachers participate in caregiving activities. The items are: attend to children when crying; encourage children's autonomy; play with children every day; talk to children when changing diaper; and hold children while feeding. Each item is rated from 1 (never) to 5 (always).
The second section of the questionnaire is comprised of eight Likert-type items designed to assess the degree to which child-care teachers describe their current job conditions. The job condition items are as follows: "I am satisfied with my job," "I cope well with children," "I get along well with my colleagues," "this daycare center has adequate resources," "I have sufficient training in childcare," "I make home visits," "I feel burnout doing this job," and "I want to quit this job." Each item is rated from 1 (never) to 5 (always). The second section also includes two categorical items to assess whether respondents want to quit their current job and reasons for wanting to quit the current job or not. The final section of the questionnaire comprises three Likert-type items designed to assess the degree to which child-care teachers describe their salary satisfaction. The items are as follows: "I get adequate salary from this job," "I manage well with this income," and "I deserve better pay." Each item is rated from 1 (never) to 5 (always).

\section{Results}

\subsection{Descriptive Analysis}

7.1.1. Caregiving Involvement. Study participants ranked each of the five caregiving measures very highly. The lowest mean score $(\mathrm{M}=4.21, \mathrm{SD}=.88)$ was found in the "hold children while feeding" category. All other mean scores were 4.72 or more with a high of 4.81 in the "play with children everyday" caregiving measure. Overall, participants rated themselves as highly attentive and engaged caregivers. The means of all the five items of caregiving involvement are presented in Figure 1.

7.1.2. Job Conditions. Responding to the statement "I am satisfied with my job," respondents expressed a high level of job satisfaction $(\mathrm{M}=4.10, \mathrm{SD}=1.07)$. Likewise, respondents indicated they "cope well with children" $(\mathrm{M}=$ $4.15, \mathrm{SD}=1.29)$ and "get along with colleagues" $(\mathrm{M}=4.53$, $\mathrm{SD}=.93)$. Caregivers also agreed quite strongly with the statements "the center has adequate resources" ( $M=4.15$, $\mathrm{SD}=1.17)$ and "I have sufficient training in childcare" $(\mathrm{M}=4.10, \mathrm{SD}=1.10)$. Low mean scores were observed for the statements "I make home visits" $(\mathrm{M}=2.32, \mathrm{SD}=1.51)$ and "I feel burnout doing this job" $(\mathrm{M}=3.00, \mathrm{SD}=1.38)$, and "I want to quit this job" ( $\mathrm{M}=1.80, \mathrm{SD}=1.08)$. The low mean score on quitting behavior is supported by percentage analysis from a follow up question "do you plan to quit your job soon," to which only $7.69 \%$ answered "yes." The mean scores on eight measures of job condition are presented in Figure 2.

7.1.3. Salary Satisfaction. As indicated earlier, annual individual income varied widely among respondents. Measures concerning satisfaction with salary returned mixed results. In response to the statements "I get adequate salary" $(\mathrm{M}=2.97$, $\mathrm{SD}=1.27)$, and "I manage well on my salary" $(\mathrm{M}=3.21$, SD $=1.09$ ), teachers varied a great deal in their responses with the net result being neither strongly satisfied nor dissatisfied. 


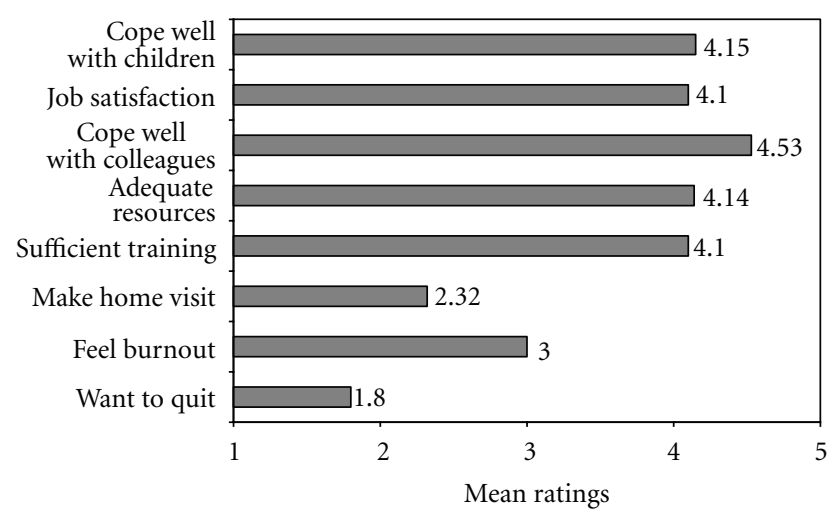

Figure 2: Mean ratings ( $1=$ never to $5=$ always $)$ for job condition variables.

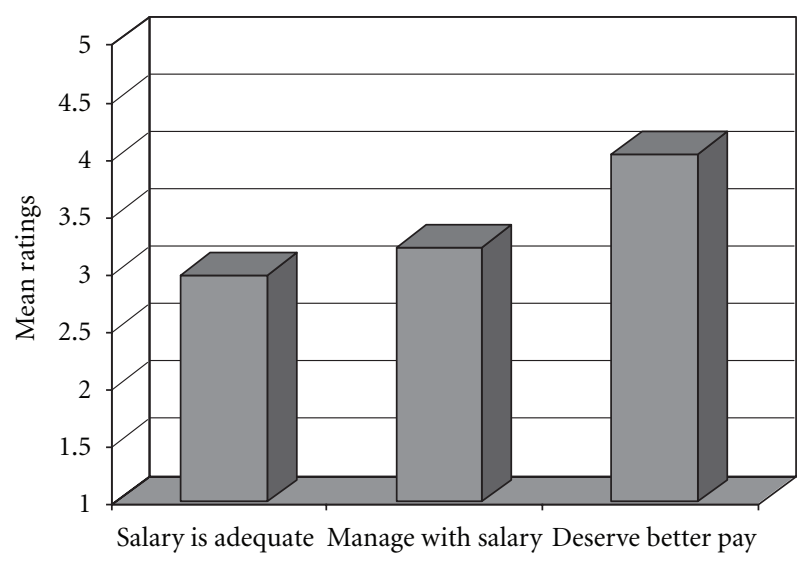

Figure 3: Mean ratings ( $1=$ strongly disagree to $5=$ strongly agree $)$ for salary satisfaction.

In response to "I deserve better pay" the respondents agreed more strongly $(\mathrm{M}=4.03, \mathrm{SD}=1.26)$. These averages are presented in Figure 3.

\subsection{Correlations}

7.2.1. Caregiving Involvement. Pearson correlation analysis showed that the statement "I attend to children when crying" is positively correlated to "I play with children everyday" ( $r=$ $.46, P<.01)$, "I talk to children when diapering" $(r=.36$, $P<.05)$, "I hold children while feeding" $(r=.56, P<.01)$, and respondents' "age" $(r=.40, P<.05)$. Furthermore, the statement "I encourage children's autonomy" was positively correlated to "I talk to children when diapering" $(r=.54$, $P<.01)$. The correlation coefficients are presented in Table 1.

7.2.2. Job Conditions. Respondents' report of the level of job satisfaction (i.e., I am satisfied with my job) was positively correlated to "I cope well with children" $(r=.66, P<.01)$, "I get along with my colleagues" $(r=.65, P<.01)$, "this center has adequate resources" $(r=.63, P<.01)$, and "I have sufficient training in childcare" $(r=.54, P<.01)$. The statement "I cope well with children" showed positive associations with "I get along with my colleagues" $(r=.59$, $P<.01)$, "this center has adequate resources" $(r=.58, P<$ $.01)$, and "I have sufficient training in childcare" $(r=.61$, $P<.01)$. Similarly, "I get along with my colleagues" was positively correlated to "this center has adequate resources" $(r=.71, P<.01)$ and "I have sufficient training in childcare" $(r=.64, P<.01)$. Furthermore, the statement "this center has adequate resources" was positively correlated to the statement "I have sufficient training in childcare" ( $r=$ $.70, P<.01)$. Finally, the statement "I feel burnout doing this job" was positively correlated to "I want to quit this job" $(r=.60, P<.01)$. The results are presented in Table 1 .

Respondents' report of the level of job satisfaction (i.e., I am satisfied with my job) was negatively correlated to "I feel burnout doing this job" $(r=-.57, P<.01)$ and "I want to quit this job" $(r=-.72, P<.01)$. The statement "I cope well with children" showed negative associations with "I feel burnout doing this job" $(r=-.62, P<.01)$ and "I want to quit this job" $(r=-.55, P<.01)$. Similarly, "I get along with my colleagues" was negatively correlated to "I feel burnout doing this job" $(r=-.37, P<.05)$ and "I want to quit this job" $(r=-.67, P<.01)$. Furthermore, the statement "this center has adequate resources" was negatively correlated to "I make home visits" $(r=-.39, P<.05)$, "I feel burnout doing this job" $(r=-.38, P<.05)$ and "I want to quit this job" $(r=$ $-.57, P<.01)$. The statement "I have sufficient training in childcare" was negatively correlated to "I feel burnout doing this job" $(r=-.35, P<.05)$ and "I want to quit this job" $(r=-.48, P<.01)$ (Table 1$)$.

7.2.3. SES Variables. Among the SES variables (age, income, education, and work hours), only age was positively correlated to the caregiving item "I attend to children when crying" ( $r=.40, P<.05)$. Income was positively correlated to "I make home visits," ( $r=.42, P<.05)$, but was negatively correlated to "I feel burnout doing this job," $(r=-.33$, $P<.05)$ and "I want to quit this job" $(r=-.38, P<.05)$ (Table 1).

\section{Regression Analysis}

Three separate regression analyses were conducted to assess the impact of selected SES (e.g., income) and job condition (e.g., cope with children, cope with colleagues, resources, and training) variables on job satisfaction, burnout, and quit measures. The regression coefficients are presented in Table 2. For job satisfaction, although all five independent variables explained $53 \%$ of the variance $(F(5,23)=5.08$, $P<.005)$ in this model, only the cope with children variable was associated with job satisfaction $(\beta=.38, P<.05)$. For burnout, while all five independent variables explained 39\% of the variance $(F(5,22)=2.86, P<.05)$, only the cope with children variable was associated with burnout $(\beta=-.56$, $P<.01)$. For quit the current job, all five independent variables accounted for $62 \%$ of the variance $(F(5,23)=7.46$, $P<.001)$ and income and cope with colleagues variables were associated with intention to quit the current job $(\beta=$ $-.31, P<.05 ; \beta=-.55, P<.01$, resp.). 
TABLE 1: Pearson correlation coefficients among caregiving involvement, job conditions, and SES variables.

\begin{tabular}{|c|c|c|c|c|c|c|c|c|c|c|c|c|c|c|}
\hline Variables & 01 & 02 & 03 & 04 & 05 & 06 & 07 & 08 & 09 & 10 & 11 & 12 & 13 & 14 \\
\hline (01) Attend & - & & & & & & & & & & & & & \\
\hline (02) Autonomy & .08 & - & & & & & & & & & & & & \\
\hline (03) Play & $.46^{* *}$ & -.17 & - & & & & & & & & & & & \\
\hline (04) Talk & $.36^{*}$ & $.54^{* *}$ & .24 & - & & & & & & & & & & \\
\hline (05) Hold & $.56^{* *}$ & .03 & .17 & .28 & - & & & & & & & & & \\
\hline (06) Job satisfaction & -.06 & .03 & -.23 & -.21 & -.04 & - & & & & & & & & \\
\hline (07) Cope with children & -.10 & .26 & -.21 & .03 & .11 & $.66^{* *}$ & - & & & & & & & \\
\hline (08) Cope with colleague & -.01 & .12 & -.16 & -.16 & .04 & $.65^{* *}$ & $.59^{* *}$ & - & & & & & & \\
\hline (09) Resources & -.03 & .07 & -.01 & -.16 & -.04 & $.63^{* *}$ & $.58^{* *}$ & $.71^{* *}$ & - & & & & & \\
\hline (10) Training & .21 & .20 & -.15 & .14 & .31 & $.54^{* *}$ & $.61^{* *}$ & $.64^{* *}$ & $.70^{* *}$ & - & & & & \\
\hline (11) Home visit & .17 & .25 & -.02 & .22 & -.12 & -.24 & -.20 & -.15 & $-.39 *$ & .23 & - & & & \\
\hline (12) Burnout & .13 & -.10 & .18 & .04 & -.04 & $-.57 * *$ & $-.62^{* *}$ & $-.37^{*}$ & $-.38^{*}$ & $-.35^{*}$ & .18 & - & & \\
\hline (13) Quit & .05 & -.05 & .23 & .25 & .12 & $-.72^{* *}$ & $-.55^{* *}$ & $-.67^{* *}$ & $-.57^{* *}$ & $-.48^{* *}$ & .19 & $.60^{* *}$ & - & \\
\hline (14) Income & .15 & .25 & -.30 & .24 & -.03 & .09 & .18 & .16 & .01 & .18 & $.42^{*}$ & $-.33^{*}$ & $-.38^{*}$ & - \\
\hline (15) Education & .14 & .15 & -.01 & .20 & -.06 & .19 & .17 & .10 & .08 & .20 & .19 & -.22 & -.29 & $.81^{* *}$ \\
\hline (16) Hours & -.27 & -.09 & -.18 & -.14 & -.09 & .24 & .16 & .12 & -.04 & .05 & -.15 & -.09 & -.07 & -.09 \\
\hline (17) Age & $.40 *$ & .24 & .15 & .15 & .26 & -.08 & -.13 & -.03 & -.13 & .00 & .20 & -.03 & .18 & .13 \\
\hline
\end{tabular}

${ }^{*} P<.05 ;{ }^{* *} P<.01$.

TABLE 2: Regression equations for job condition variables.

\begin{tabular}{|c|c|c|c|}
\hline Variables & $B$ & SE $B$ & $\beta$ \\
\hline \multicolumn{4}{|c|}{ Dependent variable $=$ job satisfaction } \\
\hline Income & -.00 & .00 & -.02 \\
\hline Cope with children & .28 & .14 & $.38^{*}$ \\
\hline Cope with colleagues & .26 & .27 & .20 \\
\hline Adequate resources & .23 & .20 & .25 \\
\hline Sufficient training & .04 & .21 & .04 \\
\hline \multicolumn{4}{|l|}{$R^{2}=.53$} \\
\hline \multicolumn{4}{|c|}{ Dependent variable $=$ burnout } \\
\hline Income & -.00 & .00 & -.23 \\
\hline Cope with children & -.56 & .21 & $-.56^{* *}$ \\
\hline Cope with colleagues & -.01 & .41 & -.01 \\
\hline Adequate resources & -.10 & .30 & -.09 \\
\hline Sufficient training & .12 & .33 & .10 \\
\hline \multicolumn{4}{|l|}{$R^{2}=.39$} \\
\hline \multicolumn{4}{|l|}{ Dependent variable $=$ quit } \\
\hline Income & -.00 & .00 & $-.31^{*}$ \\
\hline Cope with children & -.13 & .12 & -.17 \\
\hline Cope with colleagues & -.67 & .23 & $-.55^{* *}$ \\
\hline Adequate resources & -.27 & .17 & -.31 \\
\hline Sufficient training & .27 & .18 & .29 \\
\hline$R^{2}=.62$ & & & \\
\hline
\end{tabular}

\section{Discussion}

This exploratory study is an attempt to understand infanttoddler child-care teachers' involvement in caregiving tasks, the nature of their job conditions, and the relationships among involvement, job condition, and SES variables. Although the current study is exploratory and the findings may not be generalized, the data are unique and worth reporting especially because they represent samples from daycare centers located in relatively less studied rural town communities in the United States. Furthermore, the authors believe that understanding the experience of child-care teachers' working conditions and job satisfaction in relation to their training, resources, ability to cope with children and peers, and low wages contribute to the existing literature.

Descriptive analyses of self-reports suggest that infanttoddler child-care teachers in this study provide positive and/or involved caregiving [48]. They hold children while feeding, tend to them when crying, and talk with them when changing their diaper. They also encourage children's autonomy and play with them. Child-care teachers report that they cope well with the work situation in which they provide care to young children and interact positively with their superiors and colleagues as well. Respondents also report that they have sufficient training, their workplace has adequate resources, and they are satisfied with their current job. Similar to reports by other scholars $[2,16,17$, 48 ], it can be argued from the current findings that the high level of caregiving involvement and interactions and positive assessment of selected job conditions are indicative of teachers' involved caregiving. The current findings tend to lend support to the notion that adequate training, available resources at the workplace, and a high level of involvement are expected to create a stable caregiving environment for young children [10, 22, 23, 25].

Although a large proportion $(83.33 \%)$ of the respondents stated that their current income was not reasonable, only $7.69 \%$ of the respondents stated their intention to quit. This scenario is further supported by a very low average rating 
( 1.80 when 1 = never) for the item "I want to quit this job." The proportion of respondents who stated their intentions to quit is far below than the figure mentioned in previously conducted research regarding a turnover rate of $40 \%[23,28]$. Although there was only a small number of participants who answered in the affirmative to the question "do you want to quit this job?" it may be worthwhile to review the way they responded to this question. Several answers to an openended follow-up question on the reasons for wanting to quit emerged. The responses included low wages, plan to return to college to train for a higher paying job, lack of long-term benefits, and lack of social prestige. Daycare administrators may find this information useful as they develop strategies to address child-care teachers' quitting behavior.

The current findings point to the need to examine various contextual factors within and external to the teachers' work situation that may influence their moderate burnout and low turnover rate $[35,38,43]$. Teachers in the centers under study indicated a high level of satisfaction with their current jobs. While this may be a great consolation to daycare administrators, it is, nevertheless, important to bear in mind that the study was based on a very small sample. Consequently, the findings cannot be generalized to the larger population. Although a very high proportion of the subjects indicated a high degree of satisfaction with their job, it was quite disconcerting to find that respondents stated a moderate level of burnout. Moreover, over 83\% of the sample gave the response that their income was not reasonable. In light of the current findings and the findings from previous research $[27,42]$, we could anticipate that many of the respondents may leave their jobs sometime in the future, presumably once they are able to find alternative employment. This assumption can be tested in subsequent research with a sound design and large sample.

Most child-care teachers in this study, although underpaid, expressed their intention to stay at their current jobs because they want to work with young children. It appears that teachers' commitment and willingness to care for the young children may compensate for low salary. This particular view is further supported by regression analyses that are discussed later in this section. However, it can be further argued that the respondents did not want to leave their current jobs due to the low number of job prospects in their communities. Also, the sample consisted of a substantial proportion $(45 \%)$ in the age category below 30 years and a good percentage $(26 \%)$ has worked for less than three years at their present job. It is highly probable that these young caregivers have a lot of enthusiasm at present, but this enthusiasm may not be enough to predict that they can sustain this interest level in the face of low remuneration. Notwithstanding the negative interpretations of the findings, this study has indicated that to a certain extent teachers' consideration of better wages, as reported in their qualitative narratives, does play a part in their intentions to quit $[39,42]$. Subsequent empirical research can be designed to address these points.

Correlational findings suggest that teachers who attend to children when they cry are more likely to talk, hold, and play with children. Also, teachers who encourage children's autonomy are more likely to talk to children. Sufficient training encourages teachers to participate in activities related to children's autonomy and emotional regulations such as crying. These findings will encourage scholars to conduct future research investigating the degree to which teachers' involvement positively contributes to children's social and intellectual growth $[13,15]$. Furthermore, teachers who want to quit their jobs encourage less autonomy in children and cope less well with children and colleagues. Satisfied teachers cope well with children and colleagues, and sufficient training may encourage them to stay on the job. But teachers are more likely to quit if they are not satisfied with their job or feel burnout, and if they perceive that their income is less than adequate $[36,39]$. In general, while teachers' income appears to be negatively associated with their burnout and quitting behaviors, teachers' job satisfaction was positively related to their training, resources, and interactions with children and colleagues.

Regression analyses reveal that the ability to cope with children positively influences the levels of teachers' job satisfaction but negatively influences the levels of their burnout. In a similar vein, both income and the ability to cope with colleagues negatively impact teachers' quitting behavior. These findings clearly suggest that teachers' willingness and the ability to work with children would help ensure teachers' job satisfaction that, in turn, may lead to sustain the consistency of a daycare program. Furthermore, teachers' willingness and ability to work with children and colleagues and an adequate salary would encourage them to stay on the job and provide consistent caregiving [27, 30, 42, 52]. Taken together, while teachers' willingness to work with children positively predicts their levels of job satisfaction on the one hand, the ability to cope with children negatively predicts teachers' burnout on the other. Also, factors such as ability to cope with colleagues and income negatively predict teachers' quitting behavior.

In sum, child-care teachers in the current sample show high levels of involvement in their caregiving activities. They perceive that they have adequate training in childcare and the work places have resources to support their responsibilities. They also report that they cope well with their colleagues and children. Although a high percentage of the respondents were not satisfied with their present wages, they feel a moderate level of burnout and are less likely to quit their current job. More importantly, coping with children and colleagues and income appear to strongly predict teachers' job satisfaction, burnout and quitting behavior. A closer look at the relationships among these variables has significant implications for daycare administrators and program directors.

\section{Implications for Policy}

Policy makers and parents expect consistent and quality care for young children [45] and high quality care has positive effects on children's cognitive and social outcomes $[10,16]$. In light of these concerns as well as the current correlational findings, several practical implications of the current work are very clear. Center-based daycare systems 
and parents must recognize the fact that infant and toddler child-care teachers are highly involved in their professional responsibilities. It is important that administrators and policy makers encourage child-care teachers to have necessary training and provide them with adequate support to recruit and retain them for the job. It is apparent from the current findings that high levels of involvement and an increased sense of competence in coping with children may minimize teachers' perception of burnout and quitting behavior. Also, administrators and program directors should provide collegial and adaptive work environment to ensure teachers' job satisfaction. Another policy option would be to initiate and implement efforts to increase the salary for childcare teachers in daycare services. This is another important way to encourage teachers' continued commitment to their job and to recognize their significant contributions in the care of young children. Importantly, more institutional (i.e., state, federal) involvement in terms of financial and other logistical support can make jobs in the field of daycare services quite attractive to dedicated and well-trained individuals.

\section{Limitations}

Findings from the current study should be interpreted with a number of limitations in mind. The scores on the measured variables were self-rated. Had the design included a rating by the observers, different findings might have been obtained. While interviewing teachers, some interruptions occurred since they had to attend to children demanding attention. Such distractions might have influenced some of their responses. While working, some respondents might have felt uncomfortable or were physically and mentally unprepared to answer questions; thus, in order to reduce the duration of the interview, such respondents may have felt a reluctance to provide detailed information. Stated differently, due to the nature and size of the sample, there is limited generalizability of the findings across daycare centers. In addition, some data that could have proved useful in the analysis were not collected; for example, data regarding teachers' social supports could have facilitated further elaboration on job satisfaction. These topics are worthy of future study. It is important to note that it was not possible to avoid sex biases, as all respondents were female, thus limiting the ability to explore any sex differences in teachers' involvement, burnout, and job satisfaction. However, aside from these limitations, it is expected that the collected data can be considered adequate for this exploratory study that has attempted to systematically document the patterns of childcare teachers' caregiving involvement and working conditions in small urban settings in an industrialized nation.

\section{Acknowledgments}

The authors thank the Directors of the Centers involved for their permission to conduct the survey, the caregivers for their participation in the study, and Charles Burnham, James Parr, and Mark Hrastar for their help with the data collection and coding.

\section{References}

[1] U.S Bureau of Labor Statistics, Career Guide to Industries, 2010-2011 Edition, Child Day Care Services, Washington, DC, USA, 2010.

[2] U.S. Bureau of Labor Statistics, Occupational Outlook Handbook, 2010-2011 Edition, Child Care workers, Washington, DC, USA, 2010.

[3] U.S. Bureau of Labor Statistics, Occupational Employment and Wages, May 2010, Secondary School Teachers, Washington, DC, USA, 2010.

[4] M. Salkenver and J. Singerman, "The origins and significance of employer-supported child care in America," in Continuing Issues in Early Childhood Education, C. Seefelt, Ed., pp. 43-54, Merrill, Columbus, Ohio, USA, 1990.

[5] M. Segal, B. Bardige, M. Woika, and J. Leinfelder, All about Child Care and Early Education, Pearson, Boston, Mass, USA, 2006.

[6] D. Bellm and M. Whitebook, Roots of Decline: How Government Policy has De-Educated Teachers of Young Children, Center for the Study of Child Care Employment, University of California at Berkeley, Berkeley, Calif, USA, 2006.

[7] S. Helburn and B. Bergmann, America's Child Care Problem: The Way Out, Palgrave Macmillan, New York, NY, USA, 2002.

[8] J. Lombardi, Time to Care: Redesigning Child Care to Promote Education, Support Families, and Build Communities, Temple University, Philadelphia, Pa, USA, 2003.

[9] U.S. Department of Labor, Employment Characteristics of Families, 2009-10 Annual Averages, Washington, DC, USA, 2011.

[10] O. Doyle, C. Logue, and A. McNamara, "Readiness to implement a national quality framework: evidence from irish early childhood care and education centres," Child Care in Practice, vol. 17, no. 2, pp. 163-184, 2011.

[11] C. Seefeldt, Ed., Continuing Issues in Early Childhood Education, Merrill, Columbus, Ohio, USA, 1990.

[12] C. Seefeldt and A. Galper, Eds., Continuing Issues in Early Childhood Education, Prentice Hall, 2nd edition, Upper Saddle River, NJ, USA, 1998.

[13] A. J. Kahn and S. B. Kamerman, Childcare: Facing the Hard Choices, Auburn House, Dover, Mass, USA, 1987.

[14] B. M. Phillips and E. E. Morse, "Family child care learning environments: caregiver knowledge and practices related to early literacy and mathematics," Early Childhood Education Journal, vol. 39, no. 3, pp. 213-222, 2011.

[15] D. Vandell and K. Pierce, "Child care quality and children's success at school," in Early Childhood Programs for a New Century, A. Reynolds, M. Wang, and H. Walberg, Eds., pp. 115-139, Child Welfare League of America, Washington, D.C, USA, 2003.

[16] M. Burchinal, J. Roberts, L. Nabors, D. Bryant, and P. Burchinal, "Quality of center child care and infant cognitive and language development," Child Development, vol. 67, no. 2 , pp. 606-620, 1996.

[17] H. Raikes, H. Raikes, and B. Wilcox, "Regulation, subsidy receipt and provider characteristics: what predicts quality in child care homes?" Early Childhood Research Quarterly, vol. 20, no. 2, pp. 164-184, 2005.

[18] D. Vandell and R. Rosenthal, "Quality of care at schoolaged child-care programs: regulatable features, observed experiences, child perspectives, and parent perspectives," Child Development, vol. 67, no. 5, pp. 2434-2445, 1996.

[19] S. Humphrey, "The case of myself," Young Children, vol. 45, pp. 17-22, 1989. 
[20] J. Piaget, Science of Education and the Psychology of the Child, Viking, New York, NY, USA, 1969.

[21] T. H. Hawkins, Why Child Care Providers Participate in Training and Education: An Analysis of Motivation, vol. 68 of Dissertation Abstracts International Section A: Humanities and social Sciences, 2008.

[22] A. Honig and A. Hirallal, "Which counts more for excellence in childcare staff-years in service, education level or ECE coursework?" Early Child Development and Care, vol. 145, pp. 31-46, 1998.

[23] M. Whitebook and A. Eichberg, "Defining policies to improve child care workforce compensation," Young Children, vol. 57, no. 3, pp. 66-72, 2002.

[24] M. Whitebook, C. Howes, D. Phillips, and C. Pemberton, "Who cares? Child care teachers and quality of care in America," Young Children, vol. 45, pp. 41-45, 1989.

[25] A. S. Honig, "Infant/toddler education issue: practices, problems, and promises," in Continuing Issues in Early Childhood Education, C. Seefelt, Ed., pp. 61-105, Merrill, Columbus, Ohio, USA, 1990.

[26] D. Cryer and R. Clifford, Eds., Early Childhood Education and Care in the USA, Brookes, Baltimore, Md, USA, 2003.

[27] S. Kagan, R. Brandon, C. Ripple, E. Maher, and J. Joesch, "Addressing compensation and infrastructure," Young Children, vol. 57, no. 3, pp. 58-65, 2002.

[28] National Human Services Assembly and Family Strengthening Policy Center, "Low Quality Jobs Can beCostly for Employers, Families," 2008, http://www.nassembly.org/fspc/documents/ ReportNo.1.pdf

[29] J. Nelson, Why are Early Education and Care Wages so Low? A Critical Guide to Common Explanations, Foundation for Child Development, New York, NY, USA, 2001.

[30] K. Modigliani, "But who will take care of the children? Child care, women, and devalued labor," Journal of Education, vol. 168, pp. 46-69, 1986.

[31] A. G. Dworkin, Teacher Burnout in the Public School: Structural Causes and Consequences for Children, Suny, Albany, NY, USA, 1987.

[32] M. C. Schippers and R. Hogenes, "Energy management of people in organizations: a review and research agenda," Journal of Business and Psychology, vol. 26, no. 2, pp. 193-203, 2011.

[33] A. J. Cedoline, Job Burnout in Public Education: Symptoms, Causes, and Survival Skills, Teachers College, New York, NY, USA, 1982.

[34] S. Ryan and A. Hornbeck, "Mentoring for quality improvement: a case study of a mentor teacher in the reform process," Journal of Research in Childhood Education, vol. 19, pp. 79-96, 2004.

[35] B. Boyd and N. Schneider, "Perceptions of the work environment and burnout in Canadian child care providers," Journal of Research in Childhood Education, vol. 11, pp. 171-180, 1997.

[36] F. P. Brooks, "What differences unionizing teachers might make on child care in the USA: results from an exploratory study," Child \& Youth Care Forum, vol. 32, no. 1, pp. 3-22, 2003.

[37] B. Perlman and E. Hartman, "Burnout: summary and future research," Human Relations, vol. 35, pp. 283-305, 1982.

[38] G. Evans, N. Bryant, J. Owens, and K. Koukos, "Ethnic differences in burnout, coping, and intervention acceptability among childcare professionals," Child \& Youth Care Forum, vol. 33, no. 5, pp. 349-371, 2004.

[39] T. A. Cornille, R. L. Mullis, A. K. Mullis, and M. Shriner, "An examination of childcare teachers in for-profit and non-profit childcare centers," Early Child Development and Care, vol. 176, no. 6, pp. 631-641, 2006.

[40] M. Mattingly, "Sources of stress and burn-out in professional child care work," Child Care Quarterly, vol. 6, no. 2, pp. 127137, 1977.

[41] A. Stremmel, M. Benson, and D. Powell, "Communication, satisfaction, and emotional exhaustion among child care center staff: directors, teachers, and assistant teachers," Early Childhood Research Quarterly, vol. 8, pp. 221-233, 1993.

[42] M. Whitebook and L. Sakai, "Turnover begets turnover: an examination of job and occupational instability among child care center staff," Early Childhood Research Quarterly, vol. 18, no. 3, pp. 273-293, 2003.

[43] G. Petty, E. W. Brewer, and B. Brown, "Job satisfaction among employees of a youth development organization," Child \& Youth Care Forum, vol. 34, no. 1, pp. 57-73, 2005.

[44] J. Arnett, "Caregivers in day-care centers: does training matter?" Journal of Applied Developmental Psychology, vol. 10, no. 4, pp. 541-552, 1989.

[45] D. Ceglowski and E. Davis, "Assessing structural indicators of child care quality at the local level: lessons from four Minnesota counties," Child \& Youth Care Forum, vol. 33, no. 2, pp. 71-93, 2004.

[46] T. Harms, R. Clifford, and D. Cryer, Early Childhood Environmental Rating Scale (Revised Edition), Teachers College, New York, Ny, USA, 1998.

[47] D. Mill and D. Romano-White, "Correlates of affectionate and angry behavior in child care educators of preschool-aged children," Early Childhood Research Quarterly, vol. 14, no. 2, pp. 155-178, 1999.

[48] NICHD, "The NICHD study of early child care and youth development," NIH Publication 05-4318, National Institute of Child Health and Human Development, Washington, DC, USA, 2006.

[49] D. Phillips, D. Mekos, S. Scarr, K. McCartney, and M. AbbottShim, "Within and beyond the classroom door: assessing quality in child care centers," Early Childhood Research Quarterly, vol. 15, no. 4, pp. 475-496, 2000.

[50] S. Holloway and M. Reichhart-Erickson, "Child-care quality, family structure, and maternal expectations: relationship to preschool children's peer relations," Journal of Applied Developmental Psychology, vol. 10, no. 3, pp. 281-298, 1989.

[51] P. Jorde-Bloom, "Teacher job satisfaction: a framework for analysis," Early Childhood Research Quarterly, vol. 1, no. 2, pp. 167-183, 1986.

[52] M. Zaslow and I. Martinez-Beck, Eds., Critical Issues in Early Childhood Professional Development, Brooks, Baltimore, Md, USA, 2006. 


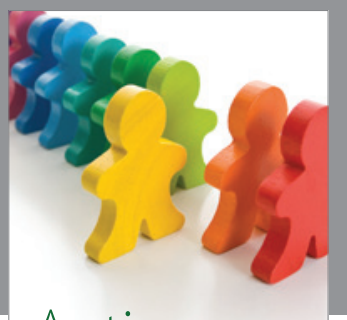

Autism

Research and Treatment
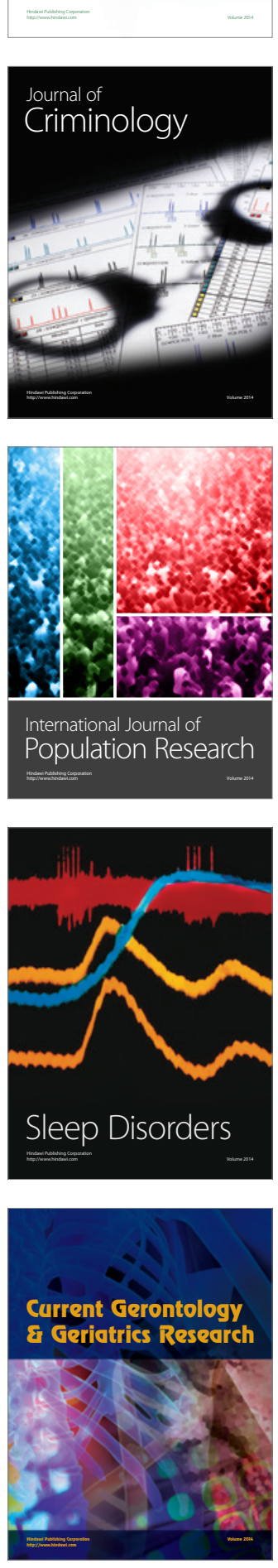
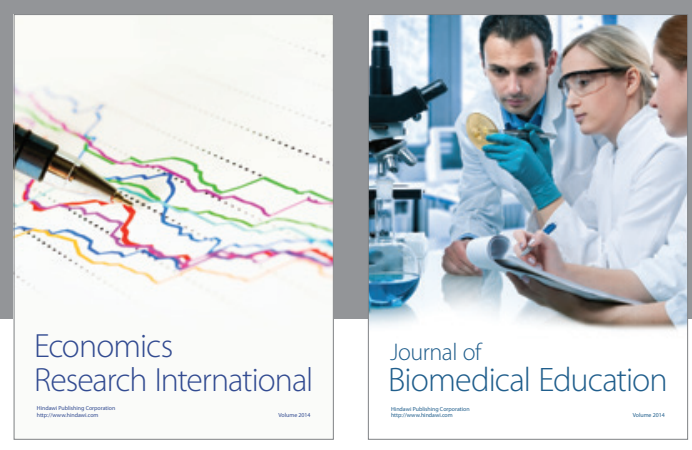

Journal of

Biomedical Education

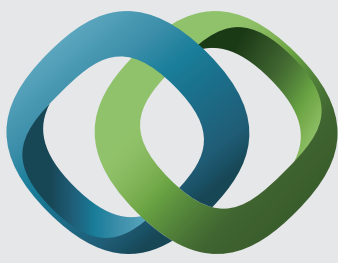

\section{Hindawi}

Submit your manuscripts at

http://www.hindawi.com
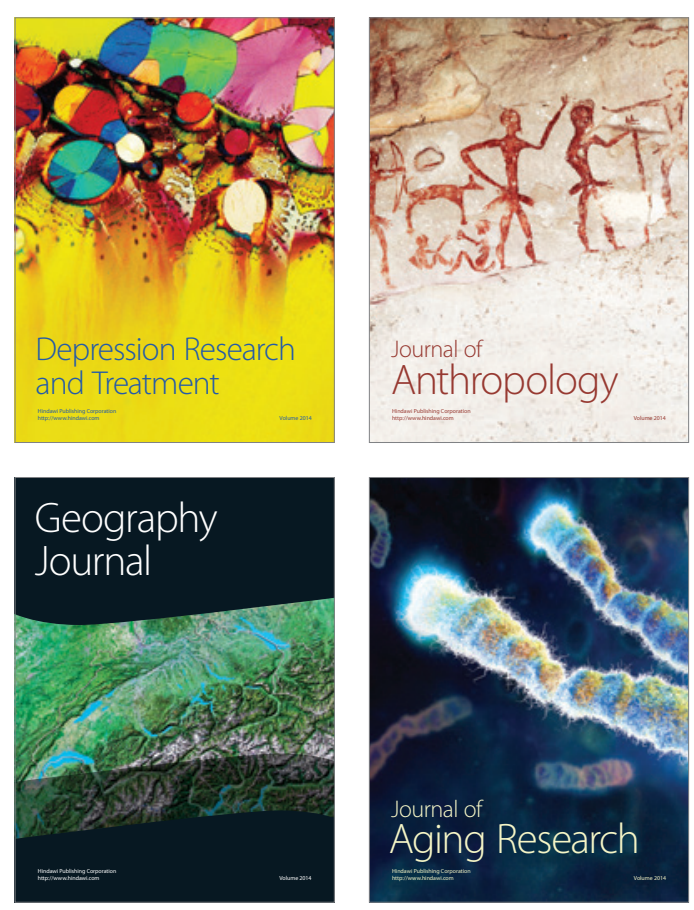

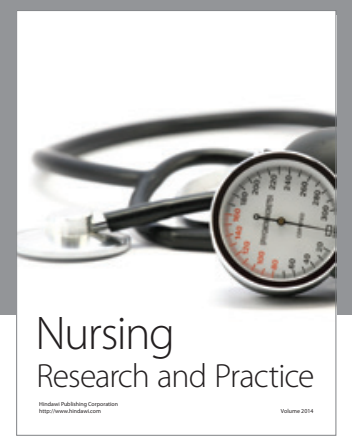

Nursing

Research and Practice

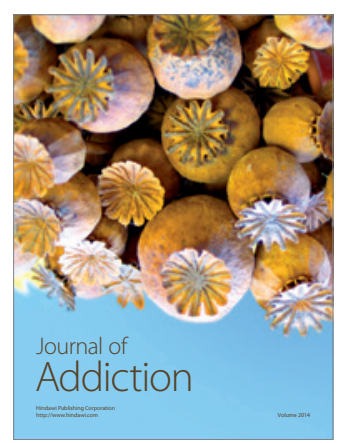

Child Development

Research

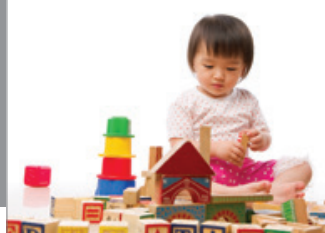

迥
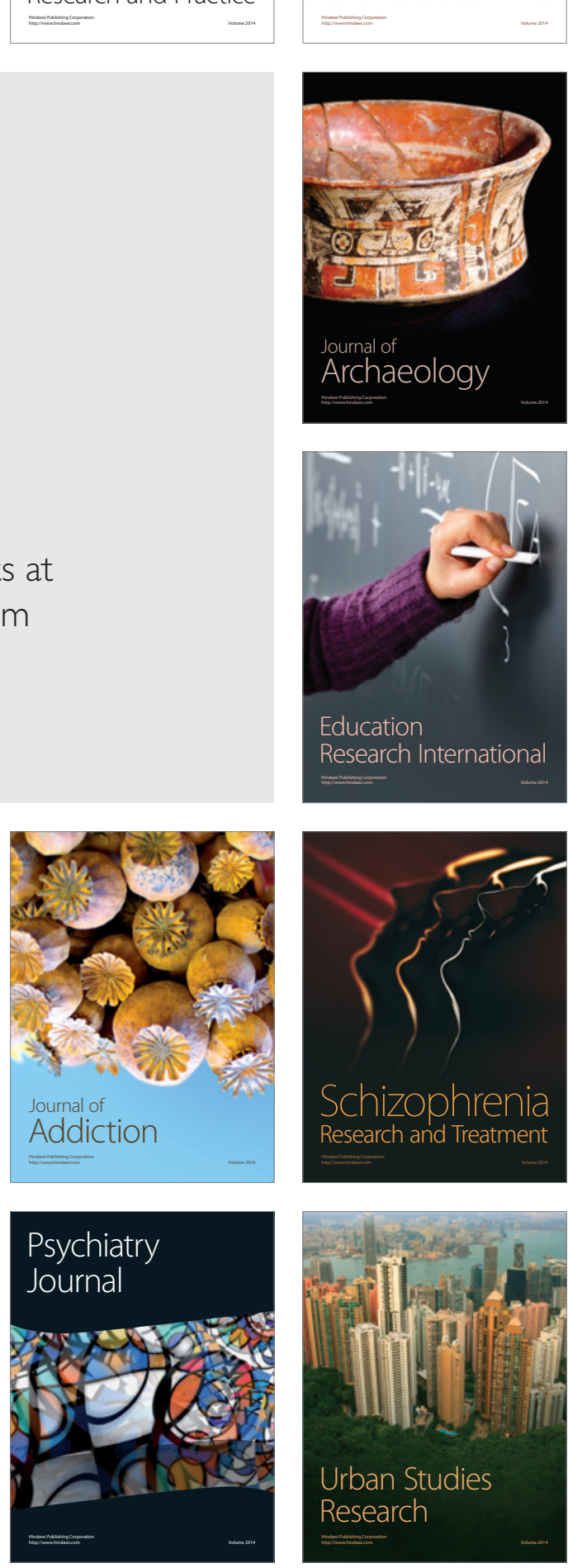